\title{
Factors influencing the heavy metal bioaccessibility in soils were site dependent from different geographical locations
}

\author{
Xiaodong Zhu ${ }^{1,2} \cdot$ Fen Yang ${ }^{1,2} \cdot$ Chaoyang Wei ${ }^{1}$
}

Received: 4 February 2015 / Accepted: 26 April 2015 / Published online: 8 May 2015

(C) Springer-Verlag Berlin Heidelberg 2015

\begin{abstract}
A soil survey was conducted in urban areas from five sites, including Beijing, Baotou, Datong, Fuyang, and Xiantao in China. The objective was to explore the most significant factors that may impact the bioaccessibility of heavy metals (Bio-HMs), including $\mathrm{As}, \mathrm{Cr}, \mathrm{Cu}, \mathrm{Pb}$, and $\mathrm{Zn}$, in soils. Twenty to 30 composite soil samples were collected at each site. The various soil properties, including $\mathrm{pH}$, particle size, $\mathrm{Fe} / \mathrm{Mn}$, and organic matter contents, were analyzed. The chemical operated forms of HMs in soils were measured by the Bureau of Reference (BCR) sequential extraction scheme, while the Bio-HMs were determined by the simple bioaccessibility extraction test (SBET) procedure. The concentrations of total heavy metals (T-HMs) in soils from different sites (cities) were in the range as As (5.69-9.86), Cr (77.42230.20), $\mathrm{Cu}$ (15.68-36.54), $\mathrm{Pb}$ (14.12-58.93), and $\mathrm{Zn}$ (38.66-183.46) $\mathrm{mg} / \mathrm{kg}$. $\mathrm{Cu}$ and $\mathrm{Pb}$ had higher relative bioaccessibilities (48-70\%) than those of As and $\mathrm{Cr}(6-$ $15 \%$ ), indicating higher health risks of the former than the latter two HMs. The Bio-HMs for various HMs were comparable to the first two or three combined BCR extracted fractions, with an exception of $\mathrm{Cu}$, whose Bio-HMs were larger than the combined three BCR fractions, indicating that $\mathrm{Cu}$ was highly accessible in soils as compared with other HMs. Factor analysis showed that all variables, including soil property
\end{abstract}

Responsible editor: Zhihong Xu

Chaoyang Wei

weicy@igsnrr.ac.cn

1 Key Laboratory of Land Surface Pattern and Simulation, Institute of Geographic Sciences and Natural Resources Research, Beijing 100101, China

2 University of the Chinese Academy of Sciences, Beijing 100049, China parameters and BCR extracted fractions, could be represented by three common factors extracted with higher than 0.5 loadings and $\sim 80 \%$ cumulative contribution to the total variance. Among the three common factors, factor 1 , containing mainly $\mathrm{pH}$, texture, and $\mathrm{Fe} / \mathrm{Mn}$ variables, and factor 3, containing mainly organic matter variable, could be attributed to geographical regions, while factor 2, containing mainly BCR extracted fractions, could be ascribed to relative bioaccessibility of HMs (R-Bio-HMs). Interactive mapping of the main factors and cluster analysis were consistent, which supported the "site gathering" of the soil sample pools, suggesting that the BioHMs in soils in different geographical localities were site dependent.

Keywords BCR - Factor analysis - Geographical location . SBET $\cdot$ Soil properties

\section{Introduction}

Heavy metal (HM) contamination has raised serious concern due to its environmental persistence, biogeochemical recycling, and ecological risks. Urban soils are the sink of large amounts of HMs from a variety of sources, including dumping wastes, waste incineration, vehicle emissions, smelting, smokestack emissions, fertilizer application, and sewage sludge production (Thornton et al. 2008). HMs in urban soils may potentially transfer to humans via ingestion, dermal contact, or breathing, especially to children due to the "hand to mouth" pathway during outdoor activities in playground and recreational areas (Laidlaw and Filippelli 2008; Li et al. 2011; Okorie et al. 2011). It has been noted that toxic metals such as arsenic (As), chromium $(\mathrm{Cr})$, copper $(\mathrm{Cu})$, lead $(\mathrm{Pb})$, and zinc $(\mathrm{Zn})$ have been increasingly entered in the urbanized areas during the past decades (Schmidt 2010; 
Thornton et al. 2008; Wong et al. 2006), consequently posing serious health risks to humans.

It is well known that the mobility, bioavailability, and ecotoxicity of HMs are dependent strongly on their specific chemical forms, or ways of binding in soils, rather than the total elemental contents (Pueyo et al. 2001). Additional studies documenting the bioaccessibility of HMs (Bio-HMs), defined as the fraction that is soluble in the gastrointestinal environment and potentially available for absorption, is the major part that may render health risks (Luo et al. 2012b; Sauve et al. 2000). On the basis of BCR sequential extraction (Rauret et al. 1999; Van Herreweghe et al. 2003), the forms of HMs are classified into exchangeable (water and acid-soluble, F1), easily reduced (iron/manganese oxyhydroxides, F2), oxidizable (organic matter and sulfides, F3), and residual fraction (F4). The occurrence and relative distribution of an element among these various phases, and the physical relation between the phases in the soils, will control an element's dissolution properties and, hence, its bioavailiability. Specific chemical forms of HMs as well as Bio-HMs have been intensively documented on obtaining bioaccessible factors to be incorporated in health risk assessment models in the study areas.

Several studies have attempted to identify which soil properties ( $\mathrm{pH}$, soil organic matter content) might have sound effects on Bio-HMs (Kim et al. 2002; Oomen et al. 2002; Ruby et al. 1999). Metal solubility was found to increase at lower while decrease at higher $\mathrm{pH}$ values (Ljung et al. 2007; Rieuwerts et al. 1998; Sauve et al. 2000). The effect of $\mathrm{pH}$ in affecting the Bio-HMs was observed to be due to its influence on most of the chemical species of HMs in soils (Basta et al. 1993). Luo et al. (2012a, b) reported that the concentrations of HMs in the particle fractions of urban soils generally increased with the decreased particle size in Hong Kong, and the optimal accumulation had happened in the finest fractions $(<50 \mu \mathrm{m})$ (Luo et al. 2012b). Iron and manganese $(\mathrm{Fe} / \mathrm{Mn})$ oxides as well as organic matter can reduce the mobility of metals in soils via adsorption reactions (Chuan et al. 1996; Zimdahl and Skogerboe 1977). Therefore, many studies often used $\mathrm{pH}$, soil texture, organic matter, and Fe/Mn oxides to predict the availability of HMs in soils (Rodrigues et al. 2013). However, it is still not clear which of these parameters is robust enough to be allowed for an estimation of the bioaccessibility, since those developed predicting models varied in sites (Hund-Rinke and Kördel 2003; Rieuwerts et al. 1998). Besides, the properties of the soils had been dramatically changed because of the increasing anthropogenic activities.

Bioaccessibility data are clearly an additional tool toward furthering our understanding of human health risk at contaminated sites and have the potential to act as a pragmatic decision-support tool (Okorie et al. 2011). Therefore, the impact factors of Bio-HMs had been widely studied. However, the dominant factors which may influence Bio-HMs in the prospect from one region to another have rarely been studied. The present study thus attempted to focus on metal chemical forms and the variability of soil properties that may be contributing to the Bio- $\mathrm{HMs}$ of $\mathrm{As}, \mathrm{Cr}, \mathrm{Cu}, \mathrm{Pb}$, and $\mathrm{Zn}$ from various types of soils in various geographical locations in
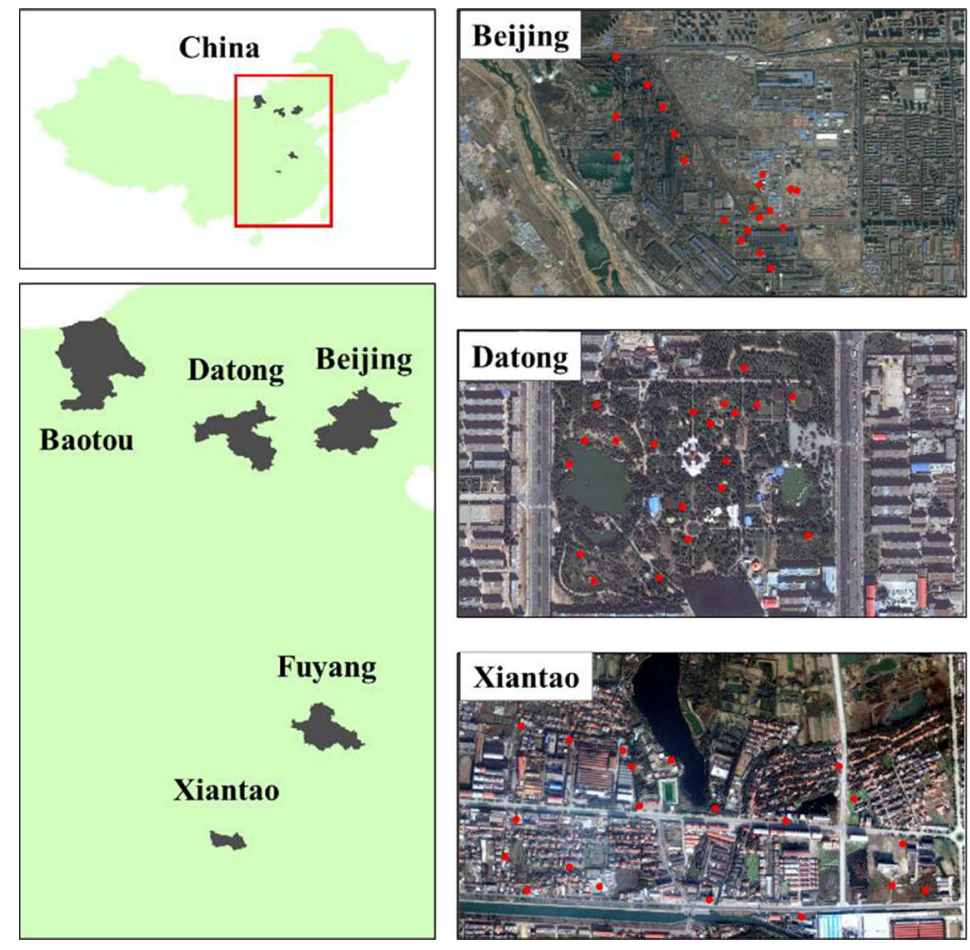

Fig. 1 A diagram showing the location of the study sites with sampling distribution
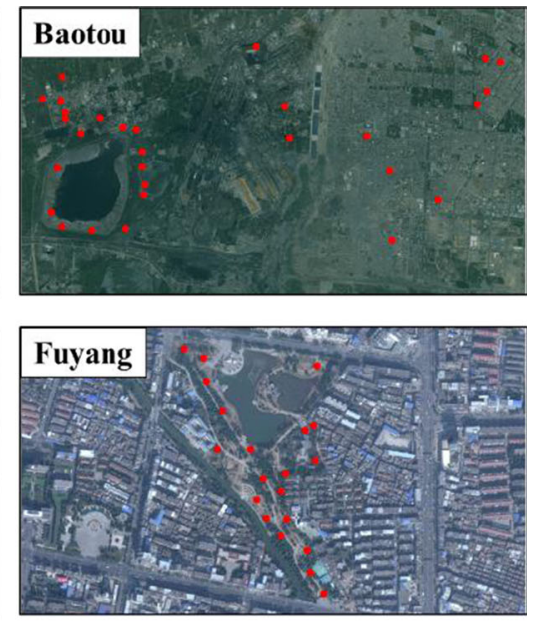

Legend

- Sampling sites

Research areas

Other areas 
China. The objectives were (1) to investigate the potential influencing factors (soil properties, heavy metal chemical forms) that may affect the Bio-HMs and (2) to examine whether these influencing factors can be categorized as a combined regional factor. The study was expected to contribute to provide basis on HM risk assessment of urban soils at various sites within various geographical belts in China.

\section{Materials and methods}

\section{Sites and sampling}

Sample collection was conducted at five sites during November 2013 to January 2014. The sites, including Beijing, Baotou, Datong, Fuyang, and Xiantao, are distributed in different areas of administration and geographical locations in China (Fig. 1). Site descriptions are summarized in Table 1.

The sampling in Beijing was performed at the former Capital Steel Iron Company, which had been notorious as a heavy contamination source in Beijing, the capital of China, and was closed and moved to Hebei province after 2007 (Cheng et al. 2013; Guo et al. 2013). In Baotou, soil samples were collected in adjacent to the steel plants in southwest of Baotou city. Sampling in Datong and Fuyang were conducted at parks in the central area of the cities, while in Xiantao, samples were collected in the central residential areas.

At each site, five subsamples within a sampling plot of $5 \mathrm{~m} \times 5 \mathrm{~m}$ were collected down to a depth of $20 \mathrm{~cm}$ to form a composite sample. Soil samples were air-dried, picked out stone and plant debris, then crashed and passed through a $2 \mathrm{~mm}$ nylon sieve. The $\mathrm{pH}$ was measured in a 1 to 2.5 soilwater suspension using a $\mathrm{pH}$ meter. The content of organic matter was analyzed using the Walkley-Black method. The particle size of the soil was determined using laser diffraction analysis method.

\section{Determination of total concentration and bioaccessibility of multi-elements}

Subsample less than $150 \mu \mathrm{m}$ in particle size was obtained by using an ultracentrifuge mill (Luo et al. 2012a). To determine the HM concentrations, a portion of the subsample was accurately weighted and digested with a concentrated acid mixture $\left(\mathrm{HNO}_{3}\right.$, $\mathrm{HF}$, and $\left.\mathrm{HClO}_{4}\right)(\mathrm{Fu}$ and Wei 2012). The total concentration of $\mathrm{As}, \mathrm{Cr}, \mathrm{Cu}, \mathrm{Pb}$, and $\mathrm{Zn}$ in the samples were measured in the digested solution using inductively coupled plasma optical emission spectrometer (ICP-OES, PE, USA). Certified soil reference (GBW-07453) was used to check the accuracies of the analysis. The recoveries of HMs were within the ranges of $84-110 \%$.

Simple bioaccessibility extraction test (SBET) (Luo et al. 2011; Madrid et al. 2008) was used to assess the bioaccessibility of $\mathrm{As}, \mathrm{Cr}, \mathrm{Cu}, \mathrm{Pb}$, and $\mathrm{Zn}$. Briefly, $50 \mathrm{ml}$ of the $0.4 \mathrm{M}$

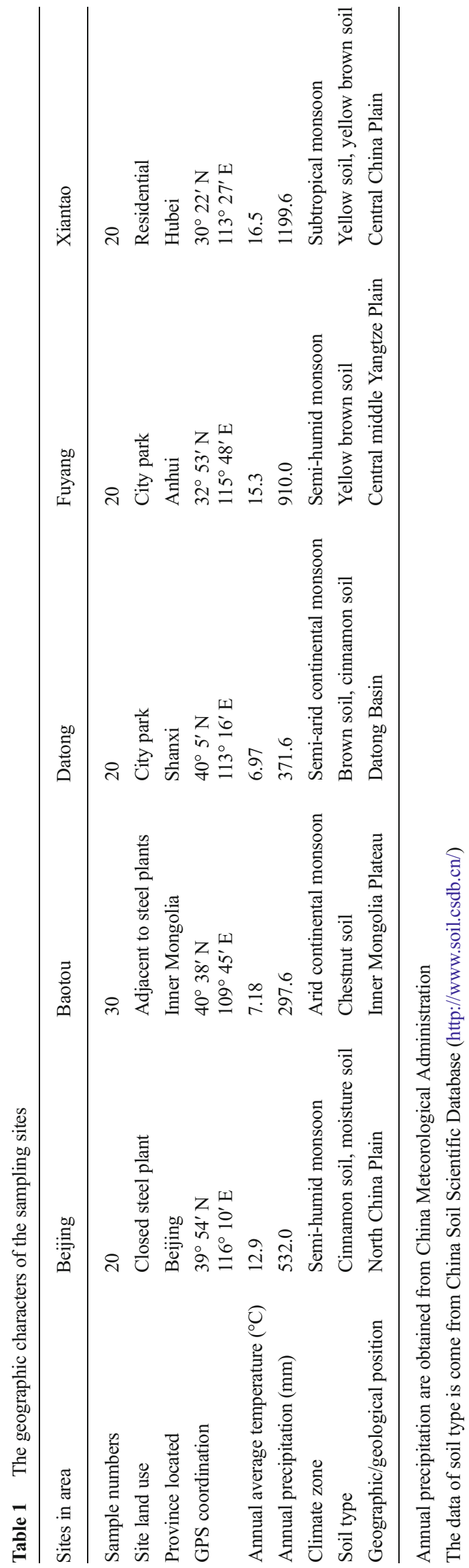


glycine extraction solution was added to $0.5 \mathrm{~g}$ of sieved $(<150 \mu \mathrm{m}$ fraction), air-dried soil material in a $100 \mathrm{ml}$ polythene centrifuge tube. The tubes were shaken end over end at $37^{\circ} \mathrm{C}$ for $1 \mathrm{~h}$ at $30 \mathrm{rpm}$. To ensure that all $\mathrm{pH}$ values were within in $0.5 \mathrm{U}$ of the starting $\mathrm{pH}(1.5)$, the $\mathrm{pH}$ was measured in part of the unfiltered extraction fluid. The mixtures were centrifuged at $3000 \mathrm{rpm}$ for 10 minafter shaking; the extracted suspension was filtered with $0.45 \mu \mathrm{m}$ cellulose acetate disk filter. The test for each sample was duplicated. Blanks and reference soil materials (GW07412a) were used in each batch of the tests to check the accuracies of the analysis. The recoveries of the tests were within the ranges of $82-119 \%$. The determination of Bio-HMs was the same as described above for T-HM concentrations.

\section{BCR sequential extraction}

Sequential extraction techniques were vastly used in determining the specific chemical forms of HMs associated with the THMs in different environmental media and to estimate the bioaccessibility of HMs. The principle of this method is based on the selective extraction of heavy metals in different physicochemical fractions of a material using specific solvents (Bruder-Hubscher et al. 2002).

In order to harmonize the various sequential extraction procedures used for HM phase analysis, a BCR three-step sequential extraction scheme was proposed by the European Community Bureau of Reference in 1992 (the Standards Measurement and Testing Program) (BCR). Subsequently, this scheme was improved as a result of further collaborative studies (Rauret et al. 1999). In this study, a revised version of the BCR sequential extraction procedure was used to test the HM phases (Baig et al. 2009; Rauret et al. 1999; Van Herreweghe et al. 2003). In brief, the forms of HMs were classified into exchangeable (water and acid-soluble, F1), easily reduced (Fe/Mn oxyhydroxides, F2), oxidizable (organic matter and sulfides, F3), and residual fraction (F4). The solution that used in this process is presented in Table 2.

\section{Statistical analysis}

Statistical analysis was carried out using SPSS 20.0 software. Correlation analysis was performed by Pearson test to reveal the relationship among various factors, including total BioHM concentrations and soil property parameters. Cluster and factor analysis were performed to identify the weight of influencing factors. Moreover, stepwise regression analysis was applied to determine the dominate factors that might influence the Bio-HMs. All data except $\mathrm{pH}$ were log transformed to reduce the variation of variables before statistical analysis (Rodrigues et al. 2013).

\section{Results}

\section{Soil properties}

The soil properties, including $\mathrm{pH}$, particle size, organic matter, and $\mathrm{Fe} / \mathrm{Mn}$ content are presented in Table 3. The $\mathrm{pH}$ values varied from 7.69 in Fuyang to 7.99 in Baotou, revealing the alkaline properties of soils at the sampling sites. The particle sizes of the soils appeared to be distinctly variable among the five sites, with soils in Fuyang and Xiantao being mainly composed of silt (69 and $64 \%$, respectively), while in Baotou, the dominant proportion was sand $(70 \%)$, and the percentages of silt in Beijing and Datong (44-46\%) were comparable to that of sand (46-47\%), indicating that soils from Fuyang and Xiantao were less coarse in texture than soils from Beijing and Datong, while soils from Baotou appeared the coarsest. Among the five sites, organic matter of the soils

Table 2 Sequential extraction procedure of BCR

\begin{tabular}{|c|c|c|c|c|}
\hline BCR forms & Fractions in representation & Extraction reagents & Extraction $\mathrm{pH}$ & Extraction processes \\
\hline F1 (step 1) & $\begin{array}{l}\text { Exchangeable, water and } \\
\text { acid-soluble (carbonates) }\end{array}$ & Solution A: acetic acid, $0.11 \mathrm{~mol} / \mathrm{l}^{1}$ & $4.5-6$ & $\begin{array}{l}1 \mathrm{~g} \text { soil sample }+40 \mathrm{ml} \text { solution } \mathrm{A} \\
\text { shaking for } 16 \mathrm{~h} \text { at } 22 \pm 5^{\circ} \mathrm{C} \\
\text { (overnight); agitation: } \\
3000 \mathrm{rpm}, 20 \mathrm{~min}\end{array}$ \\
\hline F2 (step 2) & $\begin{array}{l}\text { Easily reduced (iron/manganese } \\
\text { oxyhydroxides) }\end{array}$ & $\begin{array}{l}\text { Solution B: hydroxyl ammonium chloride, } \\
0.1 \mathrm{~mol} / 1^{1}\end{array}$ & 2 & $\begin{array}{l}\text { Residual fraction of step } 1+40 \mathrm{~m} \\
\text { solution B shaking for } 16 \mathrm{~h} \text { at } \\
22 \pm 5^{\circ} \mathrm{C} \text { (overnight); agitation: } \\
3000 \mathrm{rpm}, 20 \mathrm{~min}\end{array}$ \\
\hline \multirow[t]{2}{*}{ F3 (step 3) } & $\begin{array}{l}\text { Oxidizable (organic matter } \\
\text { and sulfides) }\end{array}$ & Solution C: hydrogen peroxide, $8.8 \mathrm{~mol} / \mathrm{l}$ & 2 & $\begin{array}{l}\text { Residual fraction of step } 2+20 \mathrm{~m} \\
\text { solution } \mathrm{C} \text { for } 2 \mathrm{~h} \text { at } 85 \pm 2{ }^{\circ} \mathrm{C} \\
\text { (repeat one time) }\end{array}$ \\
\hline & & Solution D: ammonium acetate, $1.0 \mathrm{~mol} / \mathrm{l}$ & & $\begin{array}{l}\text { Residual fraction of above }+50 \mathrm{~m} \\
\text { solution D shaking for } 16 \mathrm{~h} \text { at } \\
22 \pm 5^{\circ} \mathrm{C} \text { (overnight); agitation: } \\
3000 \mathrm{rpm}, 20 \mathrm{~min}\end{array}$ \\
\hline
\end{tabular}


Table 3 Basic statistics of soil property parameters

\begin{tabular}{lrrrrr}
\hline & \multicolumn{1}{l}{ Beijing } & \multicolumn{1}{l}{ Baotou } & \multicolumn{1}{l}{ Datong } & \multicolumn{1}{c}{ Fuyang } & \multicolumn{1}{c}{ Xiantao } \\
\hline $\mathrm{pH}$ & $7.71 \pm 0.13$ & $7.99 \pm 0.17$ & $7.79 \pm 0.10$ & $7.69 \pm 0.10$ & $7.79 \pm 0.15$ \\
Clay (\%) & $7.90 \pm 1.92$ & $3.31 \pm 1.16$ & $9.31 \pm 2.44$ & $15.73 \pm 6.26$ & $7.87 \pm 2.75$ \\
Silt (\%) & $45.69 \pm 5.93$ & $26.27 \pm 6.04$ & $44.01 \pm 5.38$ & $69.05 \pm 4.54$ & $63.9 \pm 6.93$ \\
Sand (\%) & $46.41 \pm 7.41$ & $70.43 \pm 7.07$ & $46.68 \pm 7.40$ & $15.22 \pm 4.16$ & $28.22 \pm 8.80$ \\
Organic matter (\%) & $6.68 \pm 2.23$ & $4.13 \pm 1.72$ & $5.78 \pm 1.88$ & $3.46 \pm 1.38$ & $2.63 \pm 1.03$ \\
$\mathrm{Mn}(\mathrm{mg} / \mathrm{kg})$ & $813 \pm 328$ & $1192 \pm 986$ & $453 \pm 29.0$ & $509 \pm 48.0$ & $575 \pm 87.0$ \\
$\mathrm{Fe}_{2} \mathrm{O}_{3}(\%)$ & $6.24 \pm 1.79$ & $8.83 \pm 3.56$ & $4.17 \pm 0.31$ & $4.29 \pm 0.21$ & $4.61 \pm 0.67$ \\
\hline
\end{tabular}

Data are means \pm SD

Table 4 The total, bioaccessible (Bio-HMs), relative bioaccessible (R-Bio-HMs), and BCR extracted forms of heavy metals in the soils at five sites Total (mg/kg) Bio-HMs (mg/kg) R-Bio-HMs (\%) BCR extracted forms (mg/kg)

\begin{tabular}{|c|c|c|c|c|}
\hline $\mathrm{F} 1$ & $\mathrm{~F} 2$ & F3 & $\begin{array}{l}\text { Sum (F1-2) } \\
(\mathrm{F} 1+\mathrm{F} 2)\end{array}$ & $\begin{array}{l}\operatorname{Sum}(F 1-3) \\
(\mathrm{F} 1+\mathrm{F} 2+\mathrm{F} 3)\end{array}$ \\
\hline
\end{tabular}

\begin{tabular}{|c|c|c|c|c|c|c|c|c|}
\hline \multicolumn{9}{|c|}{ Beijing $(n=20)$} \\
\hline As & $9.86 \pm 9.75$ & $0.59 \pm 0.18$ & 5.98 & $0.09 \pm 0.07$ & $0.41 \pm 0.15$ & $0.07 \pm 0.04$ & $0.50 \pm 0.20$ & $0.56 \pm 0.21$ \\
\hline $\mathrm{Cr}$ & $116.0 \pm 35.70$ & $14.44 \pm 2.23$ & 13.19 & $0.26 \pm 0.19$ & $6.35 \pm 3.10$ & $8.48 \pm 2.05$ & $6.61 \pm 3.20$ & $15.09 \pm 5.08$ \\
\hline $\mathrm{Cu}$ & $32.76 \pm 35.72$ & $15.31 \pm 11.13$ & 63.05 & $0.98 \pm 0.83$ & $7.02 \pm 8.03$ & $5.71 \pm 6.62$ & $8.00 \pm 8.84$ & $13.71 \pm 15.16$ \\
\hline $\mathrm{Pb}$ & $35.78 \pm 18.31$ & $25.20 \pm 13.83$ & 70.13 & $1.81 \pm 0.97$ & $26.68 \pm 13.71$ & $3.83 \pm 2.11$ & $28.50 \pm 14.58$ & $32.33 \pm 16.33$ \\
\hline $\mathrm{Zn}$ & $183.5 \pm 163.5$ & $116.3 \pm 146.9$ & 54.61 & $47.84 \pm 76.29$ & $73.34 \pm 73.69$ & $7.62 \pm 9.32$ & $121.2 \pm 146.2$ & $128.8 \pm 152.0$ \\
\hline \multicolumn{9}{|c|}{ Baotou $(n=30)$} \\
\hline As & $8.61 \pm 5.11$ & $0.85 \pm 0.63$ & 9.87 & $0.23 \pm 0.17$ & $0.50 \pm 0.31$ & $0.07 \pm 0.14$ & $0.73 \pm 0.31$ & $0.80 \pm 0.44$ \\
\hline $\mathrm{Cr}$ & $230.2 \pm 84.61$ & $23.75 \pm 9.36$ & 10.54 & $0.82 \pm 0.42$ & $9.17 \pm 5.02$ & $13.81 \pm 14.05$ & $9.99 \pm 5.03$ & $23.81 \pm 17.92$ \\
\hline $\mathrm{Cu}$ & $25.11 \pm 9.31$ & $7.92 \pm 1.76$ & 34.64 & $0.70 \pm 0.30$ & $3.65 \pm 1.05$ & $3.96 \pm 3.98$ & $4.35 \pm 1.07$ & $8.31 \pm 4.00$ \\
\hline $\mathrm{Pb}$ & $58.93 \pm 65.81$ & $22.54 \pm 22.22$ & 41.19 & $2.97 \pm 4.84$ & $20.15 \pm 20.09$ & $3.50 \pm 3.57$ & $23.12 \pm 19.92$ & $26.62 \pm 22.73$ \\
\hline $\mathrm{Zn}$ & $78.44 \pm 74.97$ & $35.34 \pm 38.56$ & 42.81 & $12.67 \pm 26.48$ & $20.44 \pm 16.44$ & $6.47 \pm 9.27$ & $33.11 \pm 30.00$ & $39.58 \pm 32.88$ \\
\hline \multicolumn{9}{|c|}{ Datong $(n=20)$} \\
\hline As & $7.62 \pm 7.17$ & $1.02 \pm 0.32$ & 13.39 & $0.18 \pm 0.22$ & $0.63 \pm 0.24$ & $0.13 \pm 0.09$ & $0.81 \pm 0.31$ & $0.94 \pm 0.34$ \\
\hline $\mathrm{Cr}$ & $83.46 \pm 8.01$ & $12.43 \pm 0.61$ & 15.02 & $0.93 \pm 0.42$ & $3.62 \pm 0.62$ & $7.45 \pm 1.71$ & $4.55 \pm 0.78$ & $12.00 \pm 2.07$ \\
\hline $\mathrm{Cu}$ & $36.54 \pm 48.29$ & $9.35 \pm 2.09$ & 45.25 & $0.66 \pm 0.26$ & $3.31 \pm 0.92$ & $3.69 \pm 1.98$ & $3.97 \pm 0.88$ & $7.66 \pm 2.09$ \\
\hline $\mathrm{Pb}$ & $21.28 \pm 6.74$ & $14.20 \pm 5.40$ & 66.20 & $1.47 \pm 0.67$ & $15.30 \pm 6.58$ & $3.72 \pm 2.68$ & $16.76 \pm 6.78$ & $20.48 \pm 9.03$ \\
\hline $\mathrm{Zn}$ & $40.71 \pm 24.70$ & $10.89 \pm 9.06$ & 25.69 & $13.80 \pm 15.21$ & $13.34 \pm 8.60$ & $2.49 \pm 5.50$ & $27.14 \pm 18.19$ & $29.64 \pm 21.24$ \\
\hline \multicolumn{9}{|c|}{ Fuyang $(n=20)$} \\
\hline As & $5.69 \pm 3.36$ & $0.65 \pm 0.09$ & 16.83 & $0.13 \pm 0.04$ & $0.34 \pm 0.09$ & $0.02 \pm 0.03$ & $0.47 \pm 0.10$ & $0.49 \pm 0.11$ \\
\hline $\mathrm{Cr}$ & $77.42 \pm 14.7$ & $11.44 \pm 0.48$ & 15.14 & $0.54 \pm 0.18$ & $4.15 \pm 0.86$ & $8.57 \pm 0.85$ & $4.70 \pm 0.94$ & $13.27 \pm 1.49$ \\
\hline $\mathrm{Cu}$ & $15.68 \pm 3.29$ & $7.46 \pm 1.12$ & 48.61 & $0.49 \pm 0.05$ & $3.42 \pm 0.75$ & $1.27 \pm 0.38$ & $3.92 \pm 0.77$ & $5.19 \pm 0.79$ \\
\hline $\mathrm{Pb}$ & $15.96 \pm 3.36$ & $8.78 \pm 1.70$ & 55.78 & $0.98 \pm 0.09$ & $10.98 \pm 1.86$ & $2.66 \pm 0.52$ & $11.96 \pm 1.90$ & $14.62 \pm 2.20$ \\
\hline $\mathrm{Zn}$ & $38.66 \pm 11.58$ & $3.98 \pm 4.20$ & 10.05 & $0.52 \pm 1.75^{\mathrm{a}}$ & $10.38 \pm 3.45$ & $0.84 \pm 0.89$ & $10.90 \pm 4.29$ & $11.74 \pm 4.68$ \\
\hline \multicolumn{9}{|c|}{ Xiantao $(n=20)$} \\
\hline As & $8.25 \pm 4.31$ & $0.70 \pm 0.33$ & 11.71 & $0.11 \pm 0.15$ & $0.43 \pm 0.21$ & $0.03 \pm 0.04$ & $0.54 \pm 0.33$ & $0.57 \pm 0.34$ \\
\hline $\mathrm{Cr}$ & $87.3 \pm 10.36$ & $12.41 \pm 1.01$ & 14.36 & $0.58 \pm 0.18$ & $6.64 \pm 1.61$ & $8.67 \pm 1.02$ & $7.22 \pm 1.72$ & $15.89 \pm 2.08$ \\
\hline $\mathrm{Cu}$ & $23.49 \pm 11.36$ & $11.11 \pm 2.25$ & 53.55 & $1.08 \pm 0.34$ & $5.87 \pm 1.64$ & $2.71 \pm 1.06$ & $6.95 \pm 1.88$ & $9.66 \pm 2.07$ \\
\hline $\mathrm{Pb}$ & $14.12 \pm 4.32$ & $9.45 \pm 2.87$ & 67.88 & $0.97 \pm 0.18$ & $11.02 \pm 3.32$ & $1.86 \pm 0.60$ & $12.00 \pm 3.45$ & $13.86 \pm 3.87$ \\
\hline $\mathrm{Zn}$ & $58.58 \pm 26.91$ & $10.94 \pm 19.79$ & 13.75 & $7.05 \pm 14.76$ & $13.94 \pm 9.48$ & $2.75 \pm 1.52$ & $20.99 \pm 24.00$ & $23.74 \pm 25.13$ \\
\hline
\end{tabular}

Data are means \pm SD except the column of R-Bio-HMs (\%)

${ }^{a}$ Only five samples were detected with this form 
in Beijing was the highest, followed by Datong, Baotou, Fuyang, and Xiantao. Concentrations of Mn were 813 and $1192 \mathrm{mg} / \mathrm{kg}$ in Beijing and Baotou, while the corresponding contents of $\mathrm{Fe}_{2} \mathrm{O}_{3}$ were 6.24 and $8.83 \%$, respectively, much higher than those in the other three sites $(P<0.01)$.

\section{Heavy metal concentrations}

\section{T-HMs and Bio-HMs}

The average concentrations of the total and bioaccessible As, $\mathrm{Cr}, \mathrm{Cu}, \mathrm{Pb}$, and $\mathrm{Zn}$ from all five sampling sites are presented in Table 4. The concentrations of T-HMs in soils from different sites (cities) were in the range as As (5.69-9.86), $\mathrm{Cr}$ (77.42230.20), $\mathrm{Cu}$ (15.68-36.54), Pb (14.12-58.93), and Zn (38.66183.46) $\mathrm{mg} / \mathrm{kg}$, while concentrations of Bio-HMs were in the range as As (0.59-1.02), $\mathrm{Cr}$ (11.44-23.75), $\mathrm{Cu}$ (7.46-15.31), $\mathrm{Pb}$ (8.78-25.20), and Zn (3.98-116.33) $\mathrm{mg} / \mathrm{kg}$. Fuyang had the lowest T-HMs as well as Bio-HMs, while Beijing and Baotou had significantly higher concentrations on both the total and bioaccessible fractions than those from the other sites. Both of the total and bioaccessible $\mathrm{Zn}$ in Beijing were remarkably higher than those of the other four sites, being 183.46 and $116.33 \mathrm{mg} / \mathrm{kg}$, respectively.

The relative bioaccessibility of HMs (R-Bio-HMs), defined as the percentage of Bio-HMs to T-HMs, varied in HM elements, as ranged in 10-70 \%. Among those, $\mathrm{Cu}$ and $\mathrm{Pb}$ showed higher R-Bio-HMs ranges as of 48-70\%, while As and $\mathrm{Cr}$ showed lower R-Bio-HMs as 6-15\%; the variations of R-BioZn (10-55 \%) were greater than those of other HMs (Table 4).

\section{The chemical forms of HMs}

The sequential extraction results for each HMs are presented in Fig. 2. As expected, the distribution patterns of the three forms of the same element as revealed by BCR procedure changed largely within the same site (Fig. 2). Among all the five sites, As and $\mathrm{Cr}$ contained the highest residual fractions as around $90 \%$, followed by $\mathrm{Cu}(60 \%)$ and $\mathrm{Zn}(30 \%)$, while $\mathrm{Pb}$ occupied the lowest residual fraction as only $10 \%$; the same order was seen for R-Bio-HMs (Table 4). These indicate that As and $\mathrm{Cr}$ could hardly be released under natural conditions in the sites in this study. The percentages of exchangeable F1 and oxidizable fraction $\mathrm{F} 3$ seemed to have little variation $(0-10 \%)$ for all five HMs studied, except exchangeable $\mathrm{Zn}$, which were 10-30\%. Arsenic and $\mathrm{Cr}$ contained a relatively lower easily reduced fraction $\mathrm{F} 2$, while the rest three HMs displayed greater percentages, with $\mathrm{Cu}(20 \%), \mathrm{Pb}(40-70 \%)$, and $\mathrm{Zn}(30 \%)$, indicating that the HMs varied largely in this fraction.

For comparison, the percentages of each chemical form of the elements as well as the Bio-HMs are presented in Fig. 2. Bio-HMs are generally comparable to the combined three BCR fractions Sum (F1-3) (F1+F2+F3), except Bio-Pb and Bio-Zn, which are equitable to the combined two BCR fractions Sum (F1-2), while Bio-Zn in Datong, Fuyang, and Xiantao are more close to only one fraction of BCR F1. These indicate that Bio-HMs had a fixed pattern for each HMs in this study, reflecting the differences in contribution from both area factors and the HM species itself.

\section{Factor analysis and regression analysis}

To estimate the factors that might influence the Bio-HMs, factor analysis was performed. The rotation of principal component was carried out by the varimax method. All the factors including soil properties and most HM BCR forms were included as variables, except the BCR F1 of Zn, which was excluded because only 5 of 20 samples could be detected with this form at Fuyang (Tables 4 and 5).
Fig. 2 The percentages of relative bioaccessible heavy metals (R-Bio-HMs) and BCR extracted forms to total heavy metal concentrations at various sampling sites. F1, exchangble; F2, water and acid-soluble (carbonates), F3, easily reduced (iron/manganese oxyhydroxides) oxidizable (organic matter and sulfides); Sum (F1-2) and Sum (F1-3) represent F1+F2 and F1+ $\mathrm{F} 2+\mathrm{F} 3$, respectively

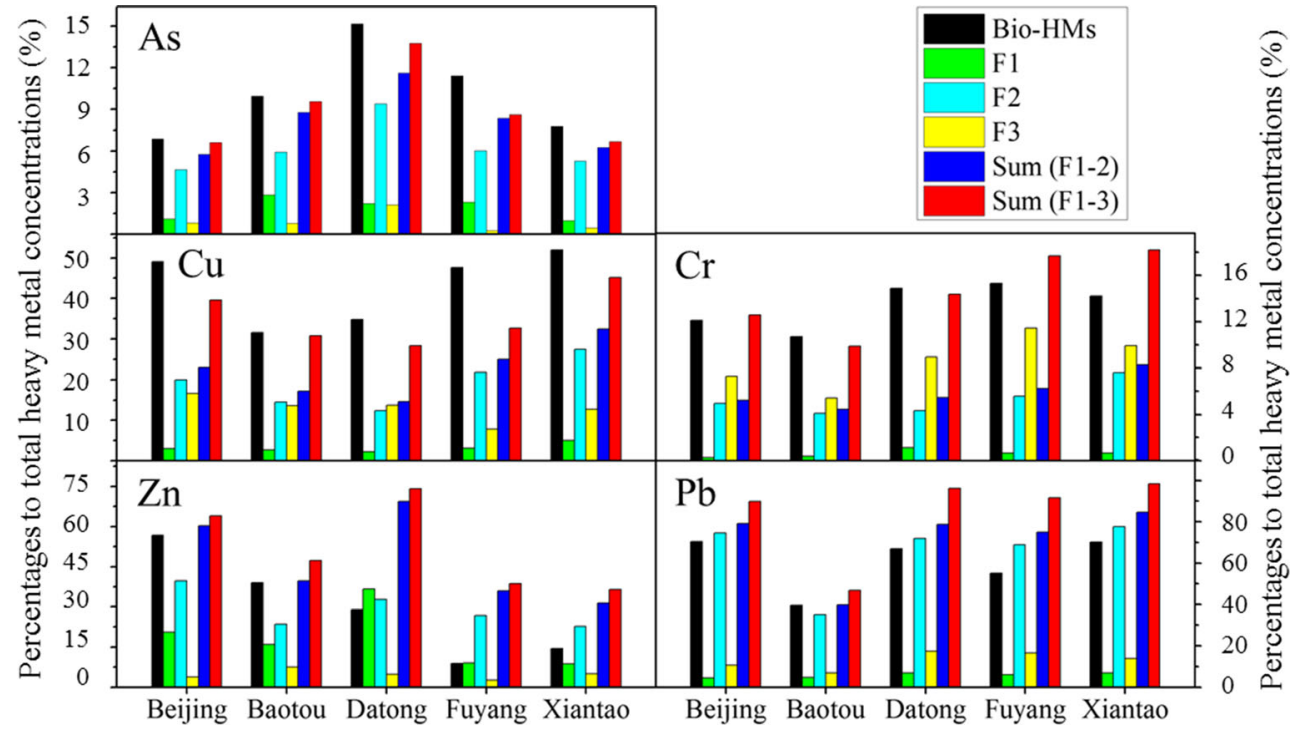




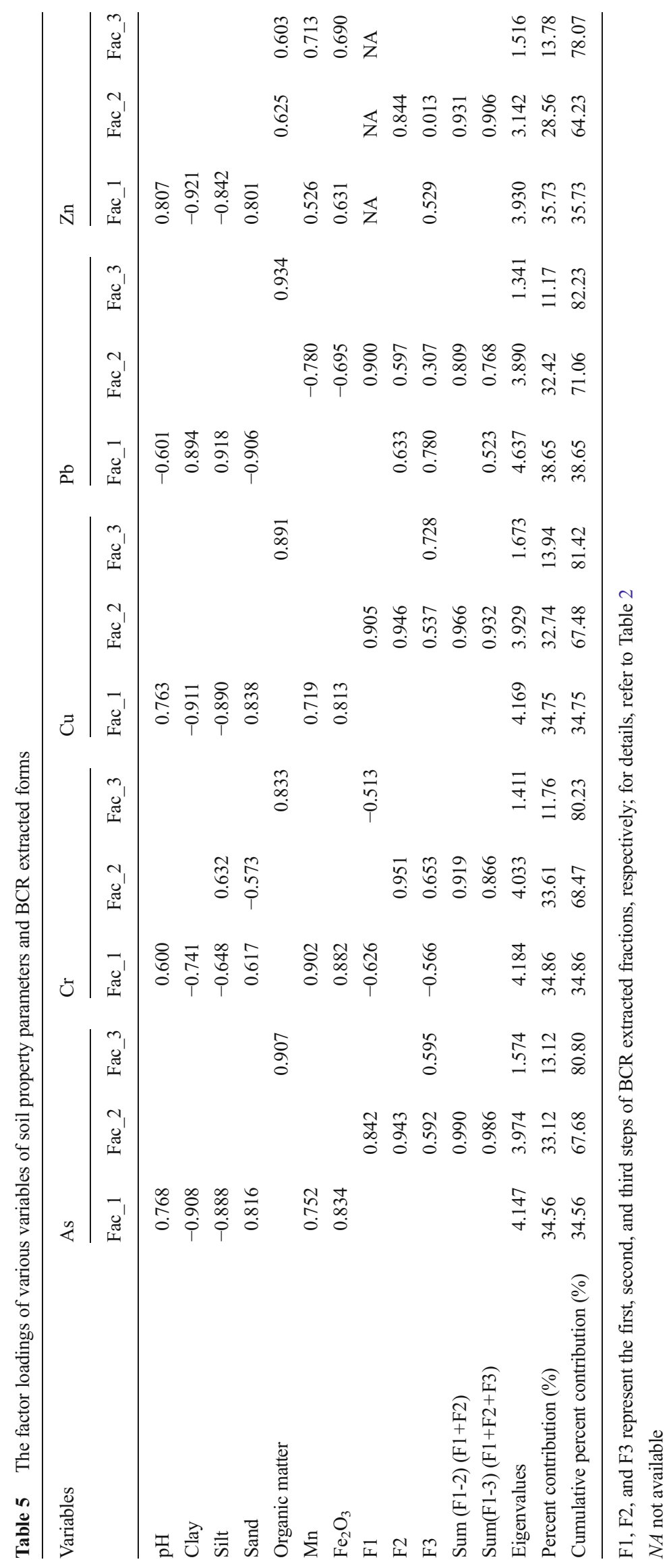


Three factors, with loadings greater than 0.5 and $~ 80 \%$ cumulative contributions to all variables, were extracted (Table 5). For all the five HMs, Fac_1 explained 34-38 \% of the total variance and had the eigenvalue of 3.9-4.7, containing high positive loadings of $\mathrm{pH}$, clay, silt, sand, $\mathrm{Mn}$, and $\mathrm{Fe}_{2} \mathrm{O}_{3}$, which can be ascribed as the soil properties factor; Fac_2 explains $28-34 \%$ of the total variance and had the eigenvalue of 3.1-4.0, containing high positive loadings of the BCR fractions of F1, F2, F3, Sum (F1-2), and Sum (F13 ), which can be attributed to BCR extraction form factors; Fac_3 occupied $11-14 \%$ of the total variance with the eigenvalue of 1.3-1.7, with high positive loadings of organic matter, which can be determined as the soil organic matter factor.

The interactive factor loadings of Fac_1 and Fac 2 showed that the main factors influencing R-Bio-HMs generally led the samples to be "site gathering" for each HMs (Fig. 3). On the scatter diagrams, among the five sites, Baotou and Fuyang left the largest space with each other as distributed on the opposite right or left, while Beijing, Datong, and Xiantao were between them with some extent of overlapping. All HMs except $\mathrm{Pb}$ had similar gathering patterns. The site gathering effect was most pronounced for Cr, while the least was seen for As (Fig. 3a, b).

Cluster analysis was also performed for the five sites using the three common factors (Fac_1, Fac_2, and Fac_3) and RBio-HMs as the variables, respectively (Fig. 4). The results were quite similar, with only a change position was seen between Beijing and Datong.

The common factors were further regressed with R-BioHMs to see the direction and extent of influence of each factor on bioaccessibility of HMs. It seems that Fac_2, representing the chemical forms of HMs in soils, had the largest and positive influence on R-Bio-HMs, while the impact of Fac_1 and Fac_3 might be comparable. The impacts of the two factors, representing soil physical-chemical properties for Fac_1 and
Fig. 3 The scatter diagrams of Fac_1 and Fac_2 of the five heavy metal elements
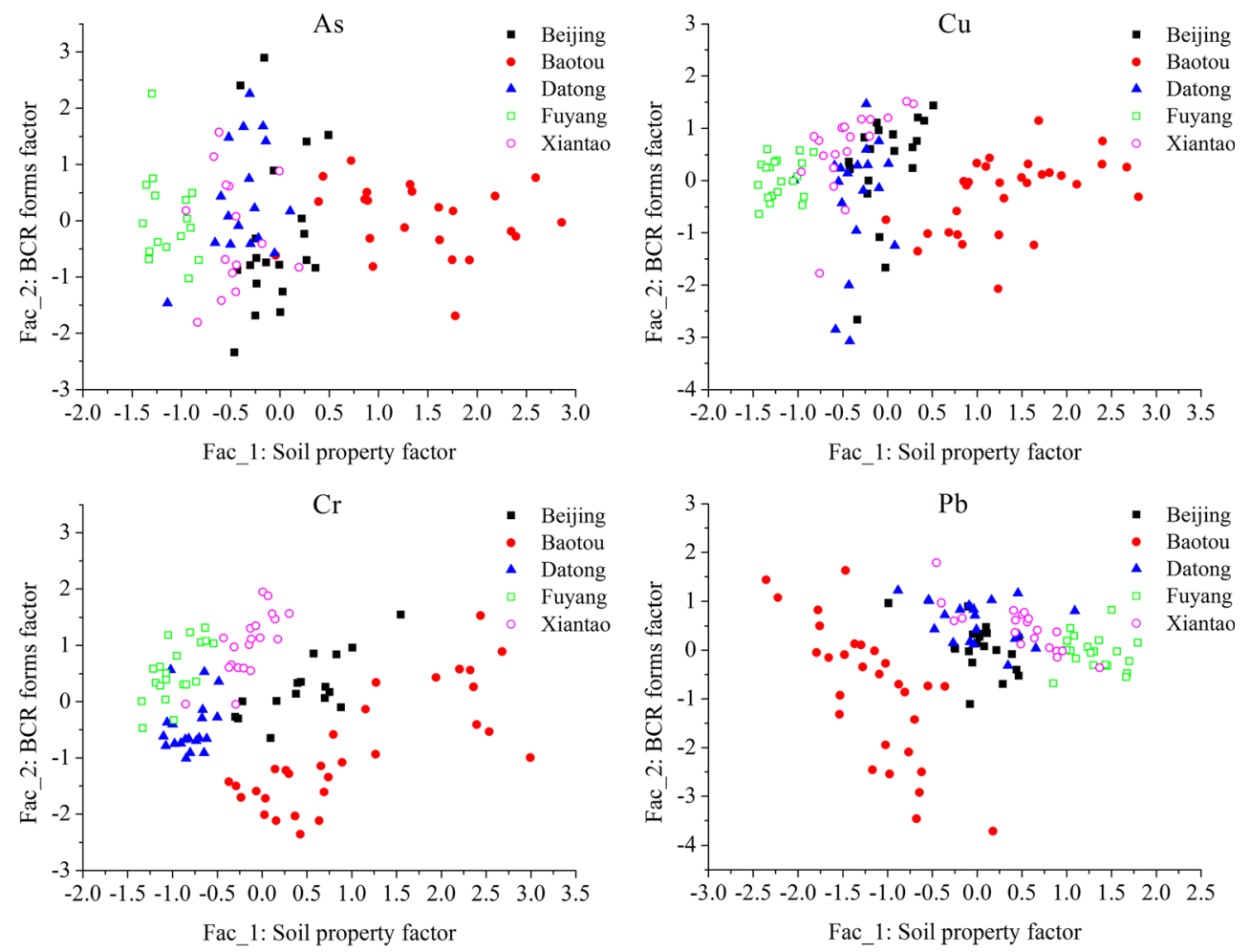

Fac_1: Soil property factor

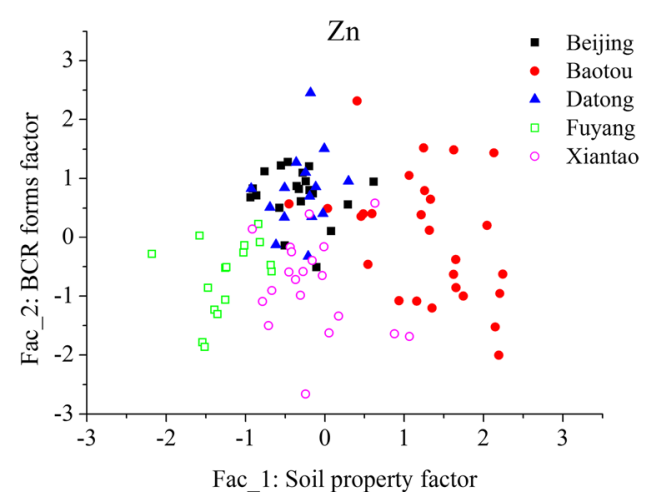


Fig. 4 The cluster dendrogram of the five sites based on a Fac 1 and Fac_2; $\mathbf{b}$ the relative bioaccessibilities (R-Bio-HMs)
Rescaled distance

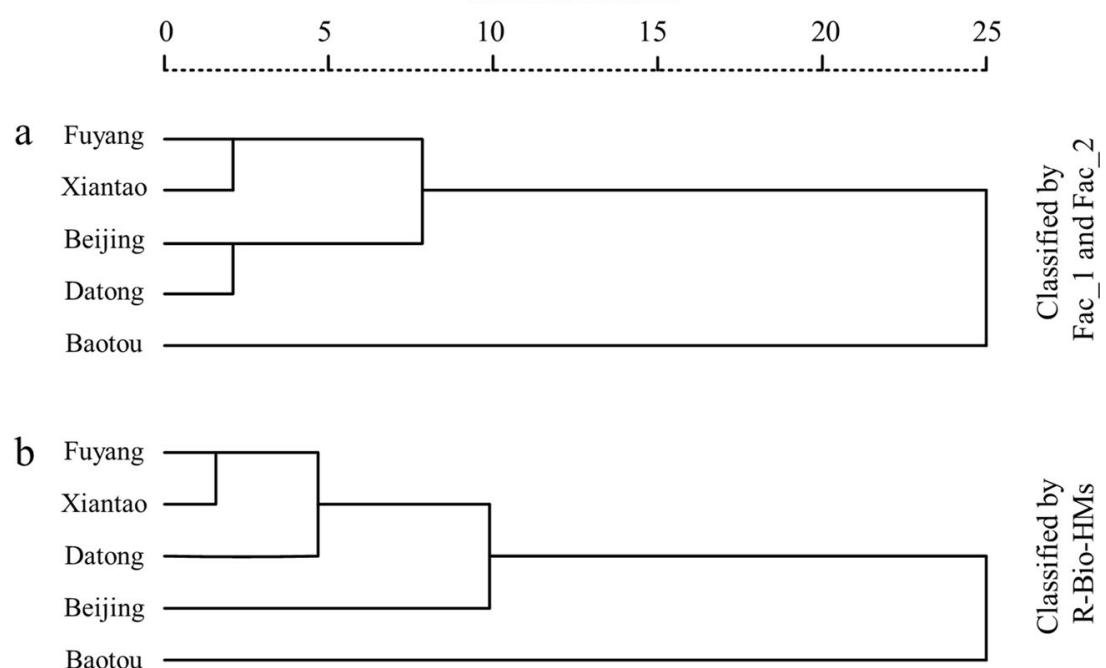

soil biological property for Fac 2, on the R-Bio-HMs, differed between $\mathrm{HMs}$ and factors themselves. For instance, for $\mathrm{Pb}$ and $\mathrm{Zn}$, the impacts were positive, whereas for $\mathrm{Cr}$, they were negative; for $\mathrm{Cu}$, Fac_1 was negative while Fac_2 was positive; for As, Fac_1 was negative while Fac_2 did not show impact (Table 6).

\section{Discussion}

The present study was conducted to explore the potential impacts of factors on the bioaccessibility of HMs in soils coming from different regions with varying climate conditions from south to north China. The relative bioaccessibility of $\mathrm{Cu}$ and $\mathrm{Pb}$ were generally higher than those of As and $\mathrm{Cr}$ (Table 4), suggesting higher human accessibility of the former than the latter two HMs. The R-Bio-HMs were generally comparable to the combined two- or three-step BCR extracted fractions (Fig. 2), suggesting that Bio-HMs were contributed by various forms of HMs in soils except the residue, which was bound to the inner crystal lattice in the minerals in soils, thus could hardly be mobilized (Ko et al. 2005; Luo et al. 2012a; Tessier et al. 1979). However, for $\mathrm{Cu}$, the R-Bio-HMs were evidently greater than the three combined BCR fractions, suggesting that $\mathrm{Cu}$ in soils could be easily mobilized and become accessible to biota in soils and human who ingest the soils (Van Herreweghe et al. 2003; Wu et al. 2015). For Pb and $\mathrm{Zn}$, the R-Bio-HMs were generally less than the combined first two steps of BCR extracted forms, indicating that the organic complexion and residue forms of HMs contributed little to the bioaccessibility of HMs in soils.

The five sites studied are distributed in different areas with varying geographical conditions (Fig. 1, Table 1), consequently demonstrating variety in soil properties (Table 3 ). The varied soil properties in sites can be attributed to, in large extent, the soil parent materials and hydrothermal conditions ( $\mathrm{Li}$ et al. 2014, 2015). However, the elevation of heavy metals in Beijing and Baotou were relatively greater than those in other sites, as the two cities might have received more intensive anthropogenic inputs (Madrid et al. 2008). In this study, factor analysis had extracted three main factors, including Fac_1, containing mainly $\mathrm{pH}$ and soil texture parameters; Fac_2, representing BCR extracted forms of HMs, and Fac_3, containing mainly organic matter (Tables 5 and 6). The interactive diagram of the loadings of Fac_1 and Fac_2 clearly supports the gathering of the samples in sites, and in the diagrams, sites in greater geographic distance are located in larger space, while sites in nearer geographic distance tend to locate in smaller space. These results may suggest that the R-BioHMs in soils, contributed mainly by the first two or three

Table 6 Factors with high loadings (absolute value $>0.5$ ) and their standardized coefficients in stepwise regression with R-Bio-HMs

\begin{tabular}{|c|c|c|c|c|c|c|c|}
\hline \multirow[t]{2}{*}{ HMs } & \multirow{2}{*}{$\begin{array}{l}\text { Fac_1 } \\
\text { Variables involved }\end{array}$} & \multirow[t]{2}{*}{ Fac_2 } & \multirow[t]{2}{*}{ Fac_3 } & Fac_1 & Fac_2 & Fac_3 & \multirow[b]{2}{*}{$R$-squared } \\
\hline & & & & \multicolumn{3}{|c|}{ Standardized coefficient ${ }^{-}$} & \\
\hline As & $\mathrm{pH}$, clay, silt, sand, $\mathrm{Mn}, \mathrm{Fe}_{2} \mathrm{O}_{3}$ & F1, F2, F3, FSum(F1-2), Sum(F1-3) & Organic matter, F3 & -0.104 & 0.941 & - & 0.897 \\
\hline $\mathrm{Cr}$ & $\mathrm{pH}$, clay, silt, sand, $\mathrm{Mn}, \mathrm{Fe}_{2} \mathrm{O}_{3}, \mathrm{~F} 1$ & Silt, clay, F2, F3, Sum(F1-2), Sum(F1-3) & Organic matter, F1 & -0.502 & 0.459 & -0.155 & 0.487 \\
\hline $\mathrm{Cu}$ & $\mathrm{pH}$, clay, silt, sand, $\mathrm{Mn}, \mathrm{Fe}_{2} \mathrm{O}_{3}$ & F1, F2, F3, Sum(F1-2), Sum(F1-3) & Organic matter, F3 & -0.21 & 0.906 & 0.239 & 0.922 \\
\hline $\mathrm{Pb}$ & pH, clay, silt, sand, F2, F3, F123 & $\mathrm{Mn}, \mathrm{Fe}_{2} \mathrm{O}_{3}, \mathrm{~F} 1, \mathrm{~F} 2, \mathrm{Sum}(\mathrm{F} 1-2), \operatorname{Sum}(\mathrm{F} 1-3)$ & Organic matter & 0.431 & 0.595 & 0.435 & 0.730 \\
\hline $\mathrm{Zn}$ & $\mathrm{pH}$, clay, silt, sand, $\mathrm{Mn}, \mathrm{Fe}_{2} \mathrm{O}_{3}, \mathrm{~F} 3$ & Organic matter, F2, Sum(F1-2), Sum(F1-3) & Organic matter, $\mathrm{Mn}, \mathrm{Fe}_{2} \mathrm{O}_{3}$ & 0.405 & 0.563 & 0.342 & 0.581 \\
\hline
\end{tabular}


BCR extracted forms, can be largely impacted by geographical regional factors. Among the five HMs, the site gathering was most pronounced for $\mathrm{Cr}$; this is reasonable since $\mathrm{Cr}$ mainly come from natural sources (Manta et al. 2002; Wei and Yang 2010), having no or little "noise" effect except in some localities with Cr-containing industries, as compared to the other four HMs, which have been usually contaminated by anthropogenic activities within and around the cities ( $\mathrm{Li}$ et al. 2001; Luo et al. 2011; Wong et al. 2006). The cluster analysis results were consistent with those of interactive factor loading diagram, indicating that sites from the north China, including Beijing, Datong, and Baotou, and sites from the south China, including Xiantao and Fuyang (Fig. 1, Table 1), were more closer in soil properties and HM bioaccessibilities, respectively. Although the gathering effects for $\mathrm{As}, \mathrm{Cu}, \mathrm{Pb}$, and $\mathrm{Zn}$ in the interactive diagram were weaker than that for $\mathrm{Cr}$, they were still clearly reflective on the geographical impacts on the HM bioaccessibilities. The results suggest that even with minor to moderate contamination of these HMs in soils, the impacts of the geographical factors on HM bioaccessibilities can still be predicted using general universe models incorporating the soil properties to obtain reasonable values in R-Bio-HMs, providing the data bank for soil HMs and properties that is large enough (Caboche et al. 2010). Hopefully, this can be expected to be realized in China since relevant data are actually available through several large scale surveys in the country during the past decades.

\section{Conclusion}

This study demonstrated that bioaccessibility of HMs in soils collected in five sites was largely impacted by soil properties, and such impacts could be differentiated with geographical localities. The main influencing factors in soils on bioaccessibility of HMs were soil pH, texture, Fe/Mn oxides, and organic matter. Future studies can be focused on building universe models incorporating these factors to predict the bioaccessibility of HMs in the soils based on geographical locations with large-scale difference. As such, more reliable health risk assessments can be obtained with reduced costs.

\begin{abstract}
Acknowledgments We thank Dr. Nan Zhang and Mr. Kai Fan for their assistance in field sampling. This study was supported by the National Science and Technology Support Program in the 12th Five-Year Plan of China "Integration and Demonstration of Environmental Monitoring Techniques for Villages and Towns" (No. 2012BAJ24B03) and the Key Project of the Knowledge Innovation Program of IGSNRR (2012ZD002).
\end{abstract}

\section{Compliance with ethical standards}

Conflict of interest The authors declare that they have no conflict of interest. This research do not involve human participants and/or animals.
All other authors have read the manuscript and have agreed to submit it in its current form for consideration for publication in the Journal;

\section{References}

Baig JA, Kazi TG, Arain MB, Shah AQ, Sarfraz RA, Afridi HI, Kandhro GA, Jamali MK, Khan S (2009) Arsenic fractionation in sediments of different origins using BCR sequential and single extraction methods. J Hazard Mater 167(1-3):745-751. doi:10.1016/j. jhazmat.2009.01.040

Basta N, Pantone D, Tabatabai M (1993) Path analysis of heavy metal adsorption by soil. Agron J 85(5):1054-1057

Bruder-Hubscher V, Lagarde F, Leroy M, Coughanowr C, Enguehard F (2002) Application of a sequential extraction procedure to study the release of elements from municipal solid waste incineration bottom ash. Anal Chim Acta 451(2):285-295

Caboche J, Denys S, Feidt C, Delalain P, Tack K, Rychen G (2010) Modelling $\mathrm{Pb}$ bioaccessibility in soils contaminated by mining and smelting activities. J Environ Sci Health, Part A: Tox Hazard Subst Environ Eng 45(10):1264-1274. doi:10.1080/10934529.2010. 493818

Cheng H, Zhao C, Liu F, Yang K, Liu Y, Li M, Peng M, Li K, Nie H, Zhang Q, Cheng X, Ruan Q, Guo L, Li Y, Huo X (2013) Mercury drop trend in urban soils in Beijing, China, since 1987. J Geochem Explor 124:195-202. doi:10.1016/j.gexplo.2012.09.007

Chuan M, Shu G, Liu J (1996) Solubility of heavy metals in a contaminated soil: effects of redox potential and $\mathrm{pH}$. Water Air Soil Pollut 90(3-4):543-556

Fu S, Wei CY (2012) Multivariate and spatial analysis of heavy metal sources and variations in a large old antimony mine, China. J Soils Sediments 13(1):106-116. doi:10.1007/s11368-012-0587-9

Guo Q, Strauss H, Chen TB, Zhu G, Yang J, Yang J, Lei M, Zhou X, Peters M, Xie Y, Zhang H, Wei R, Wang C (2013) Tracing the source of Beijing soil organic carbon: a carbon isotope approach. Environ Pollut 176:208-214. doi:10.1016/j.envpol.2013.01.035

Hund-Rinke K, Kördel W (2003) Underlying issues in bioaccessibility and bioavailability. Ecotoxicol Environ Saf 56(1):52-62. doi:10. 1016/s0147-6513(03)00050-2

Kim J-Y, Kim K-W, Lee J-U, Lee J-S, Cook J (2002) Assessment of As and heavy metal contamination in the vicinity of Duckum Au-Ag mine, Korea. Environ Geochem Health 24(3):213-225

Ko I, Chang YY, Lee CH, Kim KW (2005) Assessment of pilot-scale acid washing of soil contaminated with $\mathrm{As}, \mathrm{Zn}$ and $\mathrm{Ni}$ using the BCR three-step sequential extraction. J Hazard Mater 127(1-3):1-13. doi: 10.1016/j.jhazmat.2005.06.041

Laidlaw MAS, Filippelli GM (2008) Resuspension of urban soils as a persistent source of lead poisoning in children: a review and new directions. Appl Geochem 23(8):2021-2039. doi:10.1016/j. apgeochem.2008.05.009

Li X, C-S P, Liu PS (2001) Heavy metal contamination of urban soils and street dusts in Hong Kong. Appl Geochem 16(11):1361-1368

Li HB, Yu S, Li GL, Deng H, Luo XS (2011) Contamination and source differentiation of $\mathrm{Pb}$ in park soils along an urban-rural gradient in Shanghai. Environ Pollut 159(12):3536-3544. doi:10.1016/j. envpol.2011.08.013

Li J, Wei Y, Zhao L, Zhang J, Shangguan Y, Li F, Hou H (2014) Bioaccessibility of antimony and arsenic in highly polluted soils of the mine area and health risk assessment associated with oral ingestion exposure. Ecotoxicol Environ Saf 110:308-315. doi:10.1016/j. ecoenv.2014.09.009

Li N, Kang Y, Pan W, Zeng L, Zhang Q, Luo J (2015) Concentration and transportation of heavy metals in vegetables and risk assessment of human exposure to bioaccessible heavy metals in soil near a waste- 
incinerator site, South China. Sci Total Environ 521-522:144-151. doi:10.1016/j.scitotenv.2015.03.081

Ljung K, Oomen A, Duits M, Selinus O, Berglund M (2007) Bioaccessibility of metals in urban playground soils. J Environ Sci Health, Part A: Tox Hazard Subst Environ Eng 42(9):1241-1250. doi:10.1080/10934520701435684

Luo XS, Yu S, Li XD (2011) Distribution, availability, and sources of trace metals in different particle size fractions of urban soils in Hong Kong: implications for assessing the risk to human health. Environ Pollut 159(5):1317-1326. doi:10.1016/j.envpol.2011.01.013

Luo X-S, Ding J, Xu B, Wang Y-J, Li H-B, Yu S (2012a) Incorporating bioaccessibility into human health risk assessments of heavy metals in urban park soils. Sci Total Environ 424:88-96. doi:10.1016/j. scitotenv.2012.02.053

Luo X-S, Yu S, Li X-D (2012b) The mobility, bioavailability, and human bioaccessibility of trace metals in urban soils of Hong Kong. Appl Geochem 27(5):995-1004. doi:10.1016/j.apgeochem.2011.07.001

Madrid F, Biasioli M, Ajmone-Marsan F (2008) Availability and bioaccessibility of metals in fine particles of some urban soils. Arch Environ Contam Toxicol 55(1):21-32. doi:10.1007/s00244-0079086-1

Manta DS, Angelone M, Bellanca A, Neri R, Sprovieri M (2002) Heavy metals in urban soils: a case study from the city of Palermo (Sicily), Italy. Sci Total Environ 300(1):229-243

Okorie A, Entwistle J, Dean JR (2011) The application of in vitro gastrointestinal extraction to assess oral bioaccessibility of potentially toxic elements from an urban recreational site. Appl Geochem 26(5): 789-796. doi:10.1016/j.apgeochem.2011.01.036

Oomen AG, Hack A, Minekus M, Zeijdner E, Cornelis C, Schoeters G, Verstraete W, Van de Wiele T, Wragg J, Rompelberg CJM, Sips A, Van Wijnen JH (2002) Comparison of five in vitro digestion models to study the bioaccessibility of soil contaminants. Environ Sci Technol 36(15):3326-3334. doi:10.1021/es010204v

Pueyo M, Rauret G, Lück D, Yli-Halla M, Muntau H, Quevauviller P, López-Sánchez JF (2001) Certification of the extractable contents of $\mathrm{Cd}, \mathrm{Cr}, \mathrm{Cu}, \mathrm{Ni}, \mathrm{Pb}$ and $\mathrm{Zn}$ in a freshwater sediment following a collaboratively tested and optimised three-step sequential extraction procedure. J Environ Monit 3(2):243-250. doi:10.1039/b010235k

Rauret G, Lopez-Sanchez J, Sahuquillo A, Rubio R, Davidson C, Ure A, Quevauviller P (1999) Improvement of the BCR three step sequential extraction procedure prior to the certification of new sediment and soil reference materials. J Environ Monit 1(1):57-61
Rieuwerts J, Thornton I, Farago M, Ashmore M (1998) Factors influencing metal bioavailability in soils: preliminary investigations for the development of a critical loads approach for metals. Chem Speciat Bioavailab 10(2):61-75

Rodrigues SM, Cruz N, Coelho C, Henriques B, Carvalho L, Duarte AC, Pereira E, Romkens PF (2013) Risk assessment for $\mathrm{Cd}, \mathrm{Cu}, \mathrm{Pb}$ and $\mathrm{Zn}$ in urban soils: chemical availability as the central concept. Environ Pollut 183:234-242. doi:10.1016/j.envpol.2012.10.006

Ruby M, Schoof R, Brattin W, Goldade M, Post G, Harnois M, Mosby D, Casteel S, Berti W, Carpenter M (1999) Advances in evaluating the oral bioavailability of inorganics in soil for use in human health risk assessment. Environ Sci Technol 33(21):3697-3705

Sauve S, Hendershot W, Allen HE (2000) Solid-solution partitioning of metals in contaminated soils: dependence on $\mathrm{pH}$, total metal burden, and organic matter. Environ Sci Technol 34(7):1125-1131

Schmidt CW (2010) Lead in Air: adjusting to a new standard. Environ Health Perspect 118(2):A76-A79

Tessier A, Campbell PG, Bisson M (1979) Sequential extraction procedure for the speciation of particulate trace metals. Anal Chem 51(7): 844-851

Thornton I, Farago ME, Thums CR, Parrish RR, McGill RA, Breward N, Fortey NJ, Simpson P, Young SD, Tye AM, Crout NM, Hough RL, Watt J (2008) Urban geochemistry: research strategies to assist risk assessment and remediation of brownfield sites in urban areas. Environ Geochem Health 30(6):565-576. doi:10.1007/s10653008-9182-9

Van Herreweghe S, Swennen R, Vandecasteele C, Cappuyns V (2003) Solid phase speciation of arsenic by sequential extraction in standard reference materials and industrially contaminated soil samples. Environ Pollut 122(3):323-342. doi:10.1016/s0269-7491(02) 00332-9

Wei B, Yang L (2010) A review of heavy metal contaminations in urban soils, urban road dusts and agricultural soils from China. Microchem J 94(2):99-107. doi:10.1016/j.microc.2009.09.014

Wong CS, Li X, Thornton I (2006) Urban environmental geochemistry of trace metals. Environ Pollut 142(1):1-16. doi:10.1016/j.envpol. 2005.09.004

Wu S, Peng S, Zhang X, Wu D, Luo W, Zhang T, Zhou S, Yang G, Wan $\mathrm{H}, \mathrm{Wu} \mathrm{L}$ (2015) Levels and health risk assessments of heavy metals in urban soils in Dongguan, China. J Geochem Explor 148:71-78. doi:10.1016/j.gexplo.2014.08.009

Zimdahl RL, Skogerboe RK (1977) Behavior of lead in soil. Environ Sci Technol 11(13):1202-1207. doi:10.1021/es60136a004 